\title{
El trabajador social como intelectual orgánico. Análisis a partir de la crisis histórico-política de Chile
}

\author{
Luis Alberto Vivero Arriagada
}

\begin{abstract}
Resumen
El objetivo de este artículo es proponer una reflexión y análisis a partir de los aportes de Antonio Gramsci, particularmente desde el concepto de intelectual orgánico. En consideración al escenario que se ha generado en Chile a partir del estallido social popular, este concepto cobra una importante vigencia para el análisis de la realidad histórica. Sostenemos que el escenario de crisis social y política permitiría generar las condiciones para una reforma cultural y moral. En estas dinámicas de luchas por la hegemonía el trabajo social debería experimentar rupturas con los anclajes conservadores heredados de la dictadura y el largo periodo post autoritario de transición a la democracia.
\end{abstract}

\section{Palabras claves}

Hegemonía; intelectual orgánico; trabajo social; estallido social.

O trabalhador social como intelectual orgânico. Análise a partir da crise histórico-política do Chile

\section{Resumo}

O objetivo deste artigo é propor uma reflexão e análise a partir das contribuições de Antonio Gramsci, particularmente do conceito de intelectual orgânico. Em consideração ao cenário que foi gerado no Chile, a partir da explosão social popular, esse conceito assume uma importância significativa para análise da realidade histórica. Afirmamos que o cenário de crise social e política permitiria criar as condições para uma reforma cultural e moral. Nesta dinâmica de lutas pela hegemonia, o trabalho social deveria experimentar rupturas com os atrasos conservadores deixados pelo legado da ditadura e o longo período pós autoritário de transição democrática.

Palavras-chave

Hegemonia; intelectual orgânico; trabalho social; explosão social. 
The social worker as organic intellectual. An analysis from the historical-political crisis in Chile

\section{Abstract}

The aim of this article is to propose a reflection and an analysis with the contribution of Antonio Gramsci, particularly with the concept of organic intellectual. Considering the scene generated in Chile, since the social a popular massive mobilization, this concept assumes a significant importance to the historical analysis. We claim that the social and crisis scene could create the conditions to a cultural and moral Reform. In this dynamic of fight for hegemony, the social worker should experience the rupture against the conservative backwardness left by the dictatorship legacy and by the long period of post-authoritarian democratic transitions.

\section{Keywords}

Hegemony; organic intellectual; social work; social outburst.

Artigo recebido: março de 2021

Artigo aprovado: maio de 2021

\section{Introducción}

El presenta artículo, casi en su integridad corresponde a un trabajo presentado y publicado en la Revista Regional de Trabajo Social, n ${ }^{\circ} 59$ del año 2013, titulado "El trabajador social y su función de intelectual orgánico". En base a aquellas discusiones, hemos incorporado algunos nuevos elementos, fundamentalmente a partir del contexto de crisis sociosanitaria, y particularmente política que vive Chile, desde lo que fue el estallido social-popular de octubre de 2019.

A partir de ello, en este trabajo articulamos una discusión en torno a tres pilares, y terminamos con algunas ideas en términos de propuestas para continuar el debate. Primero, un análisis crítico respecto del ser y quehacer del trabajo social, en tanto praxis socio-ético-política, en segundo lugar, una articulación de lo anterior, a partir de los planteamientos de Gramsci respecto a la hegemonía y el rol de los intelectuales, en tercer lugar se problematiza a partir del contexto histórico-político de Chile, a la luz del estallido so- 
cial-popular de octubre de 2019, sus diferentes manifestaciones y cursos que ha ido experimentando, como el proceso constituyente y al abordaje de la crisis sociosanitaria.

Cabe señalar que el artículo original en la Revista de Trabajo Social (VIVERO, 2013), se desarrolla a partir de los primeros dos pilares, y finalmente se cierra en una síntesis, que más bien pretende dejar instalado algunos desafíos y tensiones en el campo disciplinario, como determinaciones sociohistóricas y políticas.

En lo que se aborda en el primer eje de análisis, asumimos como punto de partida, que el quehacer del trabajo social se ha visto permeabilizado en todas sus dimensiones por el neoliberalismo, como ideología totalizadora (BORÓN, 2000, 2003, 2013). Ello se materializa en la configuración de relaciones sociales fragmentadas y utilitarias, que en el quehacer profesional nos interpela a redefinir nuevos puntos de partidas y también nuevos o renovados marcos conceptuales. Se requiere por lo menos una resignificación de ciertas categorías para poder comprender un escenario, que, si bien está permeabilizado por la ideología neoliberal, hoy está expresando con mayor agudeza las contradicciones generadas por las relaciones sociales y de producción capitalista.

Los aportes de Antonio Gramsci (1981 a, 1981b, 1981c, 2012, 2015, 2018) nos ayudan a comprender la configuración del bloque histórico dominante, su capacidad de constituirse como clase hegemónica y el rol de los intelectuales orgánicos. En esta línea, parece relevante reconocer la dimensión política de la disciplina que articula los procesos formativos y su dimensión interventora en los campos institucionales. En este sentido, las/os profesionales en su condición de intelectuales orgánicos, al desplegar una acción deshistorizada y acrítica, no sólo se estará encubriendo una práctica de control que respondería a los intereses de la clase dominante, sino que, además, se estaría contribuyendo a mantener, reproducir y asegurar la capacidad de dirección y control de las clases dirigentes (GRAMSCI, 1981a, 1981b, 1981c, 2012, 2015, 2018; VIVERO, 2013). Es decir, nuestra funcionalidad en el con- 
texto de la cuestión social, al prescindir de la reflexión y análisis crítico, y, por tanto, quedándose solo en una dimensión tecno-burocrática, mayormente permita la mantención y reproducción de la hegemonía del bloque dominante.

En consecuencia, lo que observamos en el escenario de conflictividad sociopolítica, que se materializa en Chile, a partir del estallido social-popular de 2019, es la expresión material e intersubjetiva de una nueva etapa de cambios políticos y sociales. Es un contexto bastante particular y que parecía encarnar ciertas contradicciones. Por un lado, apenas hacía poco más de un año se había elegido al empresario Sebastián Piñera Echeñique, por un segundo mandato como presidente de la república, y con ello, parecía el triunfo absoluto del neoliberalismo. En tanto, en las elites neoliberales - los legítimos herederos de la herencia pinochetista y de los Chicago Boys - se respirada un aire triunfalista. Parecía entonces, el fin de la historia o la derrota total de los gobiernos progresistas. Pero las clases subalternas, dieron un giro absoluto, a partir de 19 de octubre de 2019, de la mano de un grupo de estudiantes de la educación secundaria, que con una suprema valentía insurreccional desafiaron el poder, evadiendo el pasaje del transporte público. Este contexto histórico, nos obliga a pensar y reorientar la disciplina, comprender las tensiones y contradicciones que nos muestra la realidad.

Por último, nos aventuramos a dejar planteadas algunas ideas para abrir el debate en cuanto a la necesidad de re-pensar el trabajo social a la luz del actual escenario de cambios que está experimentando América latina, protagonizado por los distintos sectores de las clases subalternas. Un escenario de conflictividad que, ante todo, ponen en cuestionamiento el modo de producción capitalista en su fase neoliberal. Estos sectores, están planteando un cambio estructural de la sociedad capitalista, y ello se expresa en prácticas sociales con la antítesis a la lógica individualista impuesta por la ideología neoliberal, lo cual nos interpela a pensar en nuevos puntos de partida, nuevas formas de acción, nuevos marcos conceptuales. Es decir, a casi 
medio siglo de lo que fue el proceso de reconceptualización, pensar en la posibilidad de una neo-reconceptualización de trabajo social latinoamericano para el siglo XXI.

\section{Las tensiones y conflictos sociopolítico del trabajo social como proyecto histórico}

El trabajador y trabajadora social, en su quehacer práctico tiene una interacción permanente en los espacios de poder y su práctica en sí misma, la definimos como una acción política (VIVERO, 2013, 2016, 2017b). Esto, por cuanto no sólo tiene que ver con la toma de ciertas decisiones en "beneficio" de los sectores o las personas que viven situaciones de pobreza o exclusión social, sino que además la configuración de su acción implica el ejerció del poder en una dialéctica que lo sitúa en una doble dimensión: por un lado se recibe un cierto mandato desde las estructuras de poder y por otro lado se ejerce un poco de ese poder del cual se es investido en su calidad de experto o intelectual (VIVERO, 2010, 2013, 2016, 2017a , 2017b).

En este ejercicio del poder, las/os profesionales se ubica en contextos que le determinan en su actual. Uno de ellos, tiene que ver en cómo el trabajo social se inscribe en el contexto de la cuestión social, como un actor más de quienes cumplen una función de reproducción del orden social burgués. Esto sin duda, tensiona a la disciplina, a pesar de su telos transformador. En esa dinámica, al insertase en el campo institucional, en la implementación de las políticas sociales, estás en si mismas, son funcionales a ese orden, por cuanto son instrumentos del estado y de los intereses de las elites (VIVERO, 2010).

Esa funcionalidad y reproducción de la ideología dominante, es una cuestión no siempre consciente, y por lo mismo, más complejo aún, pues, a pesar de que la disciplina quiera plantearse como práctica sociopolítica transformadora, la estructura ideo-política, determina en gran medida su funcionalidad. De ahí entonces, que, en esta relación de poder, que se da desde los espacios institucionales, se ejerce el 
poder técnico-instrumental con los sujetos subalternos de la acción. Los cuales no siempre son tratados como sujetos, sino más bien objetos de la acción, sujetos intervenidos. Al respecto, nos hacemos las siguientes preguntas problematizadoras: 1) ¿cuáles son los roles que debería jugar el trabajo social en tanto disciplina y campo de acción ético-político desde una perspectiva crítica y emancipadora? y, 2) ¿Es el/la trabajador/a social un/a intelectual orgánico de las clases dirigentes o estaría dispuesto/a en asumir un compromiso político y una acción transformadora con los sectores subalternos?

La práctica política del trabajo social se desarrolla en un espacio de tensiones y contradicciones de intereses, en tanto realidad histórica, se encuentra sometida a las lógicas del poder de la clase dominante. Esto es independiente, de nuestra vocación transformadora, de nuestros compromisos con las clases subalternas. que ocupa los distintos espacios del aparato del estado, configurando lo que es la superestructura del bloque histórico hegemónico (GRAMSCI, 1981a, 1981b, 1981c, 2012, 2015, 2018). Las instituciones desde las que se desarrolla la intervención responden a intereses político-ideológicos, que son invisibilizados o inconscientemente negados en el pragmatismo de la práctica del trabajo social.

Así entonces, la intervención profesional, como acción ética-política, estaría determinada por las condiciones históricas, estructuralmente determinadas, que se expresa con mayor claridad en discursos de carácter tecno-burocráticos, en el proceso de implementación de las políticas sociales, las cuales, consideramos, que operan como prácticas de contrainsurgencia social (VIVERO, 2010) $y$, que responden por lo tanto, a los intereses de mantenimiento del estatus quo, que beneficia a la clase fundamental y hegemónica (VIVERO, 2010, 2013, 2017a, 2017b).

El no reflexionar respecto de la intervención, ya la relación que tiene en las dinámicas de la estructura ideo-política, es coherente con el ethos de la clase dirigente. En la vida cotidiana, los lineamientos ideo- 
lógicos del neoliberalismo que promueve el consumismo desenfrenado, la acumulación de bienes materiales, son el demiurgo del sujeto constituido a imagen de éste. Por ello, es que una acción profesional acrítica y deshitorizada, expresada en prácticas tecnocráticas - muchas veces no asumidas consciente y críticamente - potencian el individualismo, pragmático y el emprendimiento individualista, que se reproduce incluso en el nivel familiar (VIVERO, 2013).

La visión de mundo de las elites es la razón neoliberal, la cual también tiene su expresión, en el campo del trabajo social, en las perspectivas conservadoras travestidas de una tecnocracia pragmática y poliforme. En ella, se alimenta la ilusión de una supuesta imparcialidad, una neutralidad política de la acción profesional, como si el poder no estuviese presente en ninguna de las acciones o los espacios en los cuales se desarrolla la vida social (VIVERO, 2013).

En esta hegemonía neoliberal, el trabajo social chileno en los últimos cuarenta años ha estado distante de las luchas sociales, del sujeto histórico-popular. Si bien, en el campo de la intervención, está presente como individuo que sufre los avatares de las crisis del capitalismo, no se le ve como sujeto político, sino como un sujeto de intervención. Por ello, nos parece necesario recordar que, los diecisiete años de dictadura civil y militar en Chile, dejó instalada una estructura ideológica que hasta hoy tiene sus huellas en la sociedad.

En lo que han sido estos últimos cuarenta años, la acción profesional del trabajo social, ha permanecido distante de aquellos escenarios en donde las clases subalternas, asumen un protagonismo activo y se constituyen como sujetos políticos (VIVERO, 2013, 2016, 2017a, 2017b). En el caso de Chile, no se evidenciaba de manera clara, una toma de posición orgánica desde el trabajo social. Para comprender esto, es necesario recordar que la dictadura de Augusto Pinochet que permitió que, las a las actuales elites se constituyeran como clases dirigentes. A su vez, con la dictadura, recuperaron una serie de privilegios de los que han gozado históricamente, y que sentían había en los años an- 
teriores, particularmente en el periodo comprendido entre los años 1967-1973 (GÓMEZ LEYTON, 2004). Además de lo anterior, acentuaron su control político y ello, les permitió, además, instalar las bases políticas, económicas y socioculturales de la sociedad neoliberal.

El 11 de septiembre de 1973, la burguesía oligárquica chilena, con apoyo de Estados Unidos, logra que las Fuerzas Armadas y Carabineros de Chile, traicionen su juramento de lealtad al gobierno constitucional, y lideren el derrocamiento del gobierno del Presidente Salvador Allende Gossens. De ahí en adelante se impone una dictadura militar con una importante parte participación del mundo civil, pertenecientes a sectores políticos desde la ultraderecha hasta sectores de la Democracia Cristiana. Esta dictadura cívico-militar tendrá una duración de diecisiete años, caracterizada por profundas violaciones a los Derechos Humanos, que marca un hito en la historia de Chile, que es imposible dejar fuera, si queremos hacer un análisis de la sociedad actual (VIVERO, 2017a, 2017b). Por su parte, el Trabajo Social sufre el cierre en la mayoría de las universidades en que se impartía las carreras. Asimismo, los y las profesionales serán despedidos de sus trabajos, y serán víctima de la persecución y de violación a sus derechos fundamentales (ALAYÓN, 2005; HERNÁNDEZ y RUZ, 2005). Sin duda, el Colpe de Estado de 1973 y la dictadura cívico militar en Chile, generó una profunda marca en la profesión. A más de un cuarto de siglo del retorno a la democracia, consideramos necesario que la disciplina, retome el debate interrumpido de lo que se generó en el proceso de reconceptualización, que permita sanar sus heridas.

\section{El trabajador social como intelectual orgánico}

En el magnífico análisis que hace Carlos Nelson Coutinho (2011), respecto a las contribuciones de Antonio Gramsci, al pensamiento marxista en particular y a las ciencias sociales en general. Dice al respecto que éste, sin ser "un cientista político, ni un sociólogo, ni un pedagogo, ni un antropólogo, ni un trabajador social; pero, a pesar de eso (o tal 
vez por eso mismo) tiene mucho que decir y enseñar a los cientistas políticos, a los sociólogos, a los pedagogos, a los antropólogos y a los trabajadores sociales" (COUTINHO, 2011, p. 95). En esto estamos completamente de acuerdo, y por lo mismo es que desde Gramsci nos posicionamos para analizar la función de intelectual que puede desplegar el /la trabajador/a social en su práctica cotidiana.

Gramsci en el cuaderno 11 del tomo II, se hacía la siguiente pregunta: ¿son los intelectuales un grupo autónomo o bien cada grupo social tiene su propia categoría intelectual? (CRAMSCI, 1981a, p. 186) A esto argumentaba sobre la complejidad de responder la pregunta, dado por las diversas formas que adopta el proceso histórico de formación de las distintas categorías intelectuales.

Los intelectuales tienen una función en la 'hegemonía' que el grupo dominante ejerce en toda la sociedad y en el 'dominio' sobre ella que se encarna en el Estado, y esta función es precisamente 'organizativa' o conectiva: los intelectuales tienen la función de organizar la hegemonía social de un grupo y su dominio estatal (GRAMSCI, 1981, p. 188).

Para Gramsci, todos los hombres - y mujeres - son intelectuales, pero sin embargo no todos/as llegan a desempeñar dicha función en la sociedad. Por cierto, señala el autor que, "por intelectuales hay que entender no [sólo] aquellas capas designadas comúnmente con esta denominación, sino en general toda la masa social que ejerce funciones organizativas en el sentido lato, tanto en el campo de la producción, como en el de la cultura, como en el campo administrativo-político [...]" (GRAMSCI, 1981a, p. 103).

De ahí también la distinción que el italiano hace de aquellos intelectuales que por la naturaleza de sus roles desempeñan una práctica de intelectual, como, por ejemplo, profesores, sacerdotes, e incluso filósofos. A estos los define como "tradicionales", y entre algunas de sus característica, dice que "no salen del pueblo, no conocen sus necesidades, sus aspiraciones, sus sentimientos difusos, sino que son algo 
aparte, algo apoyado en el aire, una casta exactamente" (GRAMSCI, 1981a, p. 64). Pero también cuestiona la otra posición de este tipo de intelectuales, como la de Benedetto Croce, que los define como intelectuales cosmopolitas, apartados de la realidad local, es decir, de un carácter no nacional-popular, tanto así que a Croce lo califica como el “papa laico" (GRAMSCI, 1981a).

Están los otros intelectuales, que desempeñarían un rol fundamental para la capacidad de dirección y control del bloque histórico que encarna la hegemonía de la clase fundamental: Los intelectuales orgánicos. Este bloque no es una simple alianza entre clases sociales, sino que se configura a lo menos a partir de tres momentos o escenarios distintos: 1) como las relaciones que se expresan entre estructura y súper-estructura, sin que exista supremacía de una sobre la otra; 2) cuando se logra la supremacía de la sociedad civil sobre la política y se construye un sistema hegemónico bajo la dirección de una clase fundamental que confía su gestión a los intelectuales, y por lo tanto se consolida el bloque histórico; 3) se produce el quiebre de la hegemonía de la clase dirigente, que conlleva a la construcción de un nuevo sistema hegemónico y se crea un nuevo bloque histórico (CRAMSCI, 1981a, 1981b, 2012, 2015, 2018).

La construcción de una nueva hegemonía, implica que la nueva situación histórica genera un cambio en la superestructura y sus representantes, en este caso los intelectuales, los cuales "deben ser concebidos también ellos como 'nuevos intelectuales', nacidos de la nueva situación no como continuación de la intelectualidad precedente" (GRAMSCI, 1981c, p. 302). Agreda además que,

La función de los grandes intelectuales, si permanece intacta, encuentra sin embargo un ambiente mucho más difícil para afırmarse y desarrollarse: el gran intelectual debe también él lanzarse a la vida práctica, convertirse en un organizador de los aspectos prácticos de la cultura, si quiere seguir dirigiendo; debe democratizarse, ser más actual" (GRAMSCI, 1981b, p. 17). 
Si esto lo llevamos al campo del trabajo social, resulta bastante pertinente la concepción gramsciana, por cuanto, el trabajador social tiene un ámbito de acción práctica tan amplio, que muy pocas profesiones cuentan con esa polivalencia (VIVERO, 2013). Por lo mismo permite develar las diversas contradicciones que se presentan en la realidad social (material e intersubjetiva). En la práctica cotidiana, está en gran medida la esencia disciplinaria y pragmática del trabajo social, que lo constituye como un actor privilegiado en espacios sociales diversos, pero, sin embargo, no siempre queda claro que dicha acción contribuya plenamente a la organización de las clases subalternas, que permitan elevar sus niveles de conciencia para la emancipación y verdadera transformación de las estructuras de dominación.

No olvidemos que la hegemonía de las elites, no se mantiene sólo por la imposición o la coerción, sino que también precisa de un cierto grado de consenso (GRAMSCI, 1967, 1981a, 1981b, 1981c). Así entonces, el/la trabajador/a social en su calidad de intelectual orgánico, actuaría como un agente que difunde la ideología de la clase dominante, fundamentalmente por medio del consenso.

Este es quizá el punto de inflexión del carácter ético-político del trabajo social, y de sus posibilidades de desarrollar una de la praxis transformadora, tiene que ver con visibilizar su condición y función de intelectual orgánico. En la misma línea, nos obliga a problematizar dicha función, por cuanto, en la medida que, en tanto su condición de intelectual, se implica activamente en la sociedad para generar cambios, cabe preguntarse qué tipo de cambios y/o hasta dónde llega el compromiso ético-político con los sectores subalternos. Aquí está implícito el contenido ideológico y político del trabajo social, y por lo tanto configura su condición de intelectual orgánico, pero, además, en función de qué interés opera intervención.

En el contexto de las profundas transformaciones y crisis que ha venido experimentad el modo de producción capitalista, nos genera tensiones y desafío. Se requiere una comprensión de las condiciones 
históricas, y, por tanto, una intelectualidad crítica. Por lo cual, los desafíos de este nuevo intelectual, debe darse a partir de un involucramiento activo con las luchas sociales y con el sujeto histórico-popular. Parafraseando la onceava tesis de Marx sobre Feuerbach (MARX y ENGELS, 2014), no basta, por lo tanto, solo conocer la realidad, sino que hay que involucrarse en ella para transformarla. Gramsci, al respecto nos dice lo siguiente:

El nuevo intelectual no puede ya consistir en la elocuencia, motor exterior y momentáneo de los afectos y las pasiones, sino en el mezclarse activo en la vida práctica, como constructor, organizador, persuasor permanente precisamente por no ser puro orador (GRAMSCI, 2015, p.392).

Entendemos entonces, que el trabajo social tiene una función de carácter político-social. Es decir, a pesar que el trabajador social desarrolle una intervención de carácter instrumental y tecno-burocrática, y del relato conservador apolítico, "difícilmente puede ser separada de la medición política” (GRAMSCI, 2012, p. 18).

El intelectual orgánico, piensa, problematiza el mundo desde un lugar teórico-filosófico, y lo hace tomando una posición de carácter política. Sabe muy bien a qué intereses responde, y se identifica asimismo como actor fundamental en la dinámica histórica. El trabajo social necesariamente debe hacer es proceso. No solo pensar el mundo, sino que pensarse como actor político-intelectual, y en tal sentido, tener claridad respecto de su funcionalidad. Tomar una postura político-intelectual implica definir su condición de intelectual orgánico.

Esa condición de intelectual orgánico, nos parece que además exige otra definición no menos compleja. Tener claridad y conciencia de los intereses contradictorios que se manifiestan en el entramado social en el cual actúa. En ese campo se expresa toda su funcionalidad, respecto a los intereses de las clases dominantes. Ahí es donde nos enfrentamos al dilema de asumir un rol de intelectual orgánico en beneficio de 
los intereses de las elites dominantes, o por el contrario el compromiso histórico con las clases subalterna.

\section{Los desafíos del trabajo social chileno a luz de los estallidos social- popular y el proceso constituyente}

El contexto del Chile actual, y en gran medida lo que ha vendo experimentando el capitalismo neoliberal, de cuanta de una crisis de legitimidad estructural. Es fundamental tener en cuenta que capitalismo, a lo largo de la historia ha experimentado diferentes cambios, siendo el capitalismo financiero, una de las últimas manifestaciones de esta característica inherente del capitalismo internacional (BORON, 2000, 2003, 2013). Sin lugar a dudas, una característica que Marx y Engels (2001) tenían muy claro. Al respecto, señalan que:

La burguesía ha desempeñado en la historia un papel altamente revolucionario - agregando además que ésta - no puede existir sino a condición de revolucionar incesantemente los instrumentos de producción y, por consiguiente, las relaciones de producción y, con ello todas las relaciones sociales (MARX y ENGELS, 2001, p.23).

¿Qué hizo la burguesía para enfrentar la agudización de la crisis que experimenta el capitalismo en la segunda mitad del siglo XX? En el cado de Chile, y no muy distinta en el resto de los países periféricos operó al menos en dos sentidos: 1) Haciendo uso de los instrumentos que disponía en tanto bloque histórico hegemónico, lleva al extremo su función coercitiva, lo que se materializa en los sucesivos golpes de estado en los países del cono sur, 2) Por medio del consenso, operan los intelectuales orgánicos para instalar el neoliberalismo como la nueva visión de mundo de la mano de los Chicago Boys. Así entonces, la hegemonía del capitalismo financiero se hace posible, por uso de la fuerza, y por medio del consenso. Esto último, en base a la estrategia diseñada por los intelectuales orgánicos, en implementada como 
proyecto histórico en las funciones de las instituciones de la sociedad civil, y sin duda, lideradas por sus intelectuales orgánicos, entre los cuales el trabajo social fue también un instrumento de tales fines (GRAMSCI, 2012, 2015, 2018, VIVERO, 2017b,).

Como ya lo hemos planteado más arriba, la visión de mundo de la clase hegemónica permeabilizó todos los espacios de la sociedad, y sin duda en los diversos campos intelectuales, como es el caso del trabajo social (VIVERO, 2016, 2017a, 2017b). Esta hegemonía ideológica, ha sido posible por la capacidad de dirección y control de la clase dominante, la cual comienza a sufrir un notorio agotamiento desde principios del siglo XXI. En consecuencia, lo que ocurre en Chile en octubre de 2019, es la agudización de una crisis que ya venía mostrando sus fisuras desde los primeros lustros del presente siglo. Se materializa por lo tanto una crisis, como no se había dado desde la década del setenta, y una movilización social, que, de igual manera, no se había tenido desde las luchas contra la dictadura cívico militar en los años ochenta.

Este estallido social-popular que se levanta el 18 de octubre de 2019 en Chile, son una síntesis de una serie de crisis que se habían venido produciendo, y lideradas principalmente por el movimiento estudiantil, el pueblo mapuche, y más recientemente por las luchas feministas. Estas conflictividades que se han presentado en el Chile contemporáneo no son hechos aislados, son parte de una crisis estructural de legitimidad de la llamada clase política, crisis económica, que da cuenta de la desigualdad estructural. Sin duda, el centro neurálgico de esto es la base ideológica que ha generado las condiciones estructurales para la instalación y consolidación del neoliberalismo: La Constitución de 1980 heredada de la dictadura pinochetista. Esto se puede graficar con una claridad y elocuencia, en dos consignas que representan con claridad no solo el sentir sino el saber popular: "Hasta que la dignidad se haga costumbre", y, el llamado a una "asamblea constituyente".

Sin duda lo que se genera desde el 18 de octubre de 2018 en Chile, es una situación de agudización de una crisis estructural. Esto ha evi- 
denciado una serie de confusiones, de avances y retrocesos, donde las elites luchas por seguir siendo hegemónicas. Y es justamente eso a lo que se refiere Gramsci, al describir en que consiste la crisis, al señalar que, "[...] lo viejo muere y lo nuevo no puede nacer, y en ese terreno se verifican los fenómenos morbosos más diversos" (CRAMSCI, 2018, p. 69). Pero ello es que lo que se evidencia, es un escenario complejo, lleno de indefiniciones, confusiones y contradicciones de ambas partes, desde las viejas estructuras, y aquellas que pretenden disputar la hegemonía. De acuerdo con lo anterior, lo más claro es que la clase dominante, ha perdido su capacidad de consenso, y, por lo tanto, ha dejado de ser dirigente, y solo puede ser dominante, "detentadora de la pura fuerza coercitiva" (GRAMSCl, 2018, p. 68).

En virtud de este escenario, nos parece fundamental retomar la reflexión y discusión en torno al concepto de intelectuales orgánicos que nos aporta Antonio Gramsci. Tanto el proceso de formación del trabajo social, como las diversas funciones operativas que se desarrollan en los campos institucionales de actuación profesional se cumple este rol de intelectual. Esto no se asume de manera consciente, y por lo mismo, en la implementación de las políticas sociales, como uno de los ámbitos constitutivos de la intervención profesional, va aportando en la difusión y reproducción del sentido común impuesto por la filosofía de la clase fundamental. En consecuencia, tributan a los intereses de las elites dominantes.

Cumplir rol de intelectual, no es simplemente reconocerse como tal. Por el contrario, se requiere, ante todo, comprender críticamente la función social que se cumple en el campo de las relaciones sociales, la correlación de fuerzas en las luchas de clases. Conceptualmente, podemos distinguir la función del intelectual, de acuerdo con lo que el autor de los cuadernos nos plantea en las siguientes líneas:

Cuando se distingue entre intelectuales y no intelectuales, en realidad sólo se hace referencia a la inmediata función social de la categoría profesional de los intelectuales, es decir, se tiene en 
cuenta la dirección en que gravita el mayor peso de la actividad específica profesional, si en la elaboración intelectual o en el esfuerzo nervioso-muscular (GRAMSCI, 2012, p. 13).

En resumen, lo que se vivió en Chile en octubre de 2019, que se conoce como estallido social, marca un punto de quiebre respecto de esta sociedad despolitizada que se había configurado en el periodo de absoluta hegemonía neoliberal. Esto en el campo disciplinario ha tenido un desplazamiento político interesante, por cuanto ha permitido una activa vinculación con los espacios de luchas sociales. Esto no se veía con tanta nitidez, de lo que fueron las luchas contra la dictadura, principalmente en la década del ochenta del siglo XX.

Pareciera entonces, que la crisis política y de la hegemonía neoliberal, ha provocado en el trabajo socia, un incipiente debate ético-político, acercando nuevamente a la disciplina a los espacios de luchas populares, como fue en los mejores momentos de la reconceptualización. Pero nos interpela, además, no solo a llevarnos por esta efervescencia social, sino que el desafío está en instalar los debates al interior del campo disciplinario, que permita ir reconfigurando su estatus ético político, y su función de intelectual orgánico, hoy nuevamente, al servicio de las clases subalternas.

\section{Comentarios finales}

Las clases oprimidas como motor de la historia están siendo protagonistas de su destino. Producto de esta crisis, hoy Chile tiene una posibilidad inmejorable de terminar con la constitución impuesta en Dictadura. La crisis política, ha obligado a las elites a plebiscitar la opción de escribir una constitución con todas y todos. El 25 de octubre de 2020, exactamente a un año de la marcha más grande en la historia de Chile, la opción por el "apruebo", logra un triunfo histórico, con un $78,28 \%$ y el rechazo con un $21,72 \%$ según datos del Servicio Electoral (SERVEL, 2020). De esta forma pareciera comienza a escribirse la historia del fin del neoliberalismo, y paradojalmente, en el mismo país en que fue laboratorio para su implementación hace ya medio siglo. 
Desde octubre de 2019, el trabajo social chileno nuevamente se ha ido involucrando y teniendo tener presencia en los espacios de luchas sociales. El trabajo social ha salido a las calles, enarbolando banderas junto a las clases oprimidas, como uno más de quienes viven del trabajo. Así también, otras/os han asumido el desafío de disputar el poder en los campos de la realpolitik.

Por ello, es que insistimos en la idea que es tiempo de una reorientación político-epistemológica del trabajo social, lo habíamos conceptualizado como neoreconceptualización, pero no como una copia de aquel proceso de las décadas del sesenta y setenta del siglo pasado (VIVERO, 2016). Sino que, como un llamado de atención, que nos lleve a revisar con mayor profundidad las contradicciones generadas en el actual contexto de desarrollo del capitalismo neoliberal. A partir de ello, instalar los debates y propuestas, para realizar los cambios que se requiere en el campo disciplinario.

El concepto de intelectual que nos plantea Gramsci (1981a, 1981b, 1981c, 2012, 2015, 2018) nos parece fundamental para, desde ahí problematizar el rol político que cumple el trabajo social. Tanto en la formación como en las funciones operativas que se desarrollan en los diferentes espacios de actuación profesional, sin duda, se cumple este rol de intelectual, y probablemente en el mayor de los casos, de manera no consciente.

De manera ingenua, esas prácticas reproducen el sentido común impuesto por la filosofía de la clase fundamental, tributan a los intereses de las elites. De igual forma, cumplir ese rol de intelectual, no es simplemente por reconocerse como tal, sino por la función social que se cumple en el campo de las relaciones sociales y correlación de fuerzas que ahí se acontecen como realidad histórica.

Por último, nos parece que el escenario de crisis de las hegemonías que se ha generado en Chile, a partir del estallido social popular, los aportes de Antonio Gramsci cobran una i vigencia extraordinaria para el análisis de la realidad histórica. Sostenemos que el escenario de cri- 
sis social y política permitiría generar las condiciones para una reforma cultural y moral. En particular en el campo del trabajo social, esto debería materializarse en rupturas con los anclajes conservadores y tecno-burocráticos, heredados de la dictadura y el largo periodo post autoritario de transición a la democracia.

\section{Bibliografía}

ALAYÓN, N. Trabajo social latinoamericano: a 40 años de la reconceptualización. Buenos Aires. Editorial Espacio, 2005.

BORÓN, A. Tras el Búho de Minerva. Mercado contra democracia en el capitalismo de fin de siglo. Buenos Aires: Fondo de Cultura Económica, 2000.

BORÓN, A. Estado, capitalismo y democracia en América Latina. Buenos Aires: CLACSO, 2003.

BORÓN, A. Aristóteles en Macondo. Notas sobre democracia, poder y revolución en América Latina. Chile. Construyendo América, 2013.

COUTINHO, C. N. Marxismo y política. La dualidad de poderes y otros ensayos. Chile: LOM Ediciones, 2011.

GOMEZ LEYTON, J. Las fronteras de la democracias. Chile. Editorial Lom, 2004.

GRAMSCI, A. Cuadernos de la cárcel. Tomo I. México: Ediciones ERA S.A., 1981a. GRAMSCI, A. Cuadernos de la cárcel. Tomo II. México: Ediciones ERA S.A., 1981b. GRAMSCI, A. Cuadernos de la cárcel. Tomo III. México: Ediciones ERA S.A., 1981c. GRAMSCI, A. Los intelectuales y la organización de la cultura. Buenos Aires: Nueva Visión, 2012.

GRAMSCI, A. Antología. México. Editorial Siglo XXI, 2015.

GRAMSCI, A. Pasado y presente. Cuadernos de la cárcel. España. Editorial Gedis, 2018.

HERNÁNDEZ, J.; RUZ, O. La Reconceptualización en Chile. En: ALAYÓN, N. Trabajo social latinoamericano: a 40 años de la reconceptualización. Buenos Aires. Editorial Espacio, 2005, p. 85-101.

PORTELLI, H. Gramsci y el bloque histórico. Argentina: Siglo XXI, 2003.

MARX, K.; ENGELS, F. El Manifiesto Comunista. Buenos Aires. Bureau Editores, 2001. 
MARX, K.; ENGELS, F. La ideología alemana. España: Ediciones Akal, 2014.

SERVEL. Resultado Plebiscito Nacional 2020. 2020. Disponible en: https:// www. plebiscitonacional2020.cl/plebiscito-nacional-2020-fue-la-mayor-votacion-de-la-historia-de-chile/

VIVERO, L. Las políticas públicas como prácticas de contra-insurgencia social. Revista de Ciencias Sociales, Venezuela, v.16, n. 3, Universidad del Zulia (LUZ) Maracaibo-Venezuela, 2010.

VIVERO, L. El trabajador social y su función de intelectual orgánico. Revista Regional de Trabajo Social, Año 27, n. 59, 2013. EDICIÓN EN LÍNEA.

VIVERO, L. El Trabajo Social en la era neoliberal: Desafíos para una neo-reconceptualización, En: VIDAL, Paula (Coord.). Trabajo Social en Chile: Un siglo de Trayectoria. Santiago: RIL Editores, 2016, p. 175-196.

VIVERO, L. El imaginario crítico del Trabajo Social chileno post-dictadura: Avances, tensiones y desafíos. En: SERRANO, Borja Castro; FLOTTS, Marcela (Ed.). Imaginarios de transformación. El trabajo social revisitado. Chile. Editorial Ril, 2017a, p. 131-158.

VIVERO, L. Trabajo Social entre el sentido común, hegemonía y praxis: Un análisis basado en Gramsci. Revista Latinoamericana de Ciencias Sociales, Niñez y Juventud, v. 15, n. 1, p. 547-563, 2017b.

\section{Nota}

1 Trabajador Social, Magíster en Ciencias Sociales Aplicadas, Doctor Procesos Sociales y Políticos de América Latina. Académico Departamento de Trabajo Social, Universidad Católica de Temuco - Chile. Nº ORCID 0000-0002-6459-1386. E-mail: luisvive@gmail.com 


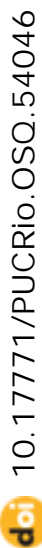

